\title{
LAGU MENIDURKAN ANAK PADA MASYARAKAT BANJAR: Kajian Bentuk, Makna, dan Fungsi
}

\author{
Noor Adeliani \\ MTsN Banjar Selatan, Jalan Mahligai Banjarmasin \\ E-mail: adelia.ani@gmail.com
}

\begin{abstract}
This research is intended to find out the form, the meaning and the function of the lyrics of Banjarese Lullabies. The method used is descriptive qualitative using Ricoeur's hermeneutic approach to understand the lyrics in Banjarese Lullabies. This study found that (1) the lyrics of Banjarese Lullabies have two forms; free and bound forms; (2) the meaning of the lyrics of the lyrics of Banjarese Lullabies contains request, prayer, education, introduction of religion, and advice, (3) the function of the lyrics of Banjarese Lullabies are referential function, expressive function, directive function and aesthetic function. This research also indicates that the similar research should be carried out continously to prevent the lyrics of Banjarese Lullabies from extinction.
\end{abstract}

Kata kunci: lirik lagu, bentuk, makna, dan fungsi, masyarakat Banjar.

\section{LATAR BELAKANG}

Pada masyarakat Banjar di Kalimantan Selatan sudah lama dikenal tradisi mengayun anak bayi. Tradisi ini baik dalam acara-acara yang bersifat ritual dan terkait dengan keyakinan maupun dalam keseharian. Dalam acara yang bersifat ritual dan terkait dengan keyakinan adalah baayun bidan (bapalas bidan), baayun madibin, baayun wayang, dan baayun Mulud. ${ }^{1}$ Adapun mengayun anak bayi dalam keseharian adalah untuk menidurkannya, karena dengan diayun si anak bayi akan tertidur pulas dan lama.

Dalam hal keseharian itu, tradisi ibu-ibu masyarakat Banjar jika menidurkan anak bayinya selalu dengan cara mengayun. Mengayun anak ini ada yang mengayun biasa dan ada yang badundang. Mengayun biasa adalah mengayun dengan berayun lepas sedang mengayun badundang adalah

${ }^{1}$ Alfani Daud, Islam dan Masyarakat Banjar: Deskripsi dan Analisis Kebudayaan Banjar, (Jakarta: PT Raja Grafindo, 1997), h. 245-247. 
mengayun dengan memegang tali ayunan. Yang lebih menarik adalah menidurkan anak ini sang ibu sambil bernyanyi (bakurui), bernyanyi dengan suara merdu berayun-ayun atau mendayu-dayu. Lirik lagu ini sangat puitis. Liriknya antara lain seperti ini:

Guring-guring anakku guring

Guring diakan dalam pukungan/dalam ayunan

Anakku nang bungas lagi bauntung.

Hidup baiman mati baiman.

Lagu menidurkan anak merupakan tradisi lisan, karena ia hanya disampaikan dengan bahasa lisan. Lirik lagu itu sekaligus sebagai hasil budaya masyarakat yang menggambarkan kehidupan masyarakat di masa lampau, dapat digunakan untuk menyampaikan pujian, hasrat, dan doa agar anak bayinya menjadi orang yang beriman, berbakti kepada kedua orang tuanya, dan berguna bagi bangsa dan Negara.

Menurut penelusuran penulis, baik melalui internet, laporan penelitian maupun buku-buku yang penulis baca, tulisan tentang lirik lagu menidurkan anak pada masyarakat Banjar: kajian bentuk, makna, dan fungsi belum pernah dilakukan. Namun tulisan yang sejenis dengan tulisan ini pernah dilakukan oleh Permata $^{2}$ membahas tentang Bentuk, Fungsi, dan Makna Mantra Dayak Ngaju, Condrat $^{3}$ Mantra Dayak Maayan: Kajian Bentuk, Fungsi, dan Makna, Saberi ${ }^{4}$ Mantra Banjar, Analisis Bentuk, Fungsi, Makna, dan Penandanya.

Tulisan tentang tradisi lisan yang dimuat di jurnal internasional, yakni antara lain pertama, Campbell ${ }^{5}$ dalam artikelnya berjudul Masonic Song in Scotland: Folk Tunes and Community menelusuri pada persoalan yang meliputi lagu-lagu rakyat dan komunitasnya. Objeknya berupa lagu-lagu rakyat dari Freemasonry; kedua, Akesson ${ }^{6}$ dengan artikelnya yang berjudul Oral/Aural Culture in Late

${ }^{2}$ Lihat Yuni Permata. Analisis (Mantra Dayak. Ngaju) Bentuk, Fungsi, dan Maknanya. (Tesis). (Banjarmasin: FKIP Unlam, 2011), h. 51-85.

${ }^{3}$ Lihat Riastinadya Condrat, Mantra Dayak Maanyan Kajian Bentuk, Fungsi, dan Makna. (Tesis). (Banjarmasin: FKIP Unlam, 2012), h. 56-73.

${ }^{4}$ Lihat Saberi. Mantra Banjar, Analisis Bentuk, Fungsi, Makna, dan Penandanya. (Tesis). (Banjarmasin: FKIP Unlam, 2010), h. 51-68.

${ }^{5}$ Lihat Katherine Campbell. "Masonic Song in Scotland: Folk Tunes and Community" dalam Oral Tradition Journal, Volume 27, Nomor 1, (Culombia: University of Missouri, 2012), h. 88-100.

${ }^{6}$ Lihat Ingrid Akesson. "Oral/Aural Culture in Late Modern Society? Traditional Singing as Professiolized Genre and Oral-Derived Expession”, dalam Oral Tradition Journal, Volume 27, Nomor 1, (Culombia: University of Missouri, 2012), h. 58-79. 
Modern Society? Traditional Singing as Professionalized Genre and Oral- Derived Expression membicarakan beberapa ekspresi dan elemen dari kelisanan dalam masyarakat modern, peran, fungsi dan batas-batas ekspresi tersebut.

Tulisan berjudul Lirik Lagu Menidurkan Anak Pada Masyarakat Banjar: Kajian Bentuk, Makna, dan Fungsi ini dimaksudkan sebagai salah satu upaya melestarikan lirik lagu menidurkan anak masyarakat Banjar agar keberadaanya dapat dipertahankan sebagaimana mestinya. Melalui tulisan ini, teks lirik lagu menidurkan anak masyarakat pada Banjar yang selama ini masih tersebar secara sporadik dalam bentuk lisan akan dikumpulkan untuk kemudian dianalisis bentuk, makna, dan fungsinya yang menjadi pendukung sebagai produk budaya bernuansa religius, yang telah hidup dan berkembang di tengah kehidupan masyarakat Banjar pada beberapa generasi. Penulis tertarik menulis tentang lirik lagu menidurkan anak pada masyarakat Banjar agar nilai-nilai luhur yang terkandung di dalamnya tidak hilang dari kehidupan. Di samping itu, tulisan ini menjadi urgen sekali sebagai upaya melestarikan sastra lisan masyarakat Banjar.

\section{MASYARAKAT BANJAR DAN SASTRA LISAN BANJAR}

Dalam beberapa publikasi, penduduk asli Kalimantan sering diidentifikasi dengan sebutan Orang Dayak. Identifikasi ini didasarkan pada sistem budaya dan bahasa yang mereka miliki. Bagi penduduk Kalimantan yang bahasanya banyak memperlihatkan persamaannya dengan bahasa Melayu, diidentifikasi sebagai orang Melayu menamakan diri dan kelompoknya sebagai orang Banjar. Sedangkan bagi yang tidak identik dengan bahasa Melayu diidentifikasi sebagai bahasa-bahasa Dayak dan penuturnya dinamakan Orang Dayak $^{7}$. Suryadikara menyatakan, orang Melayu yang tinggal di Provinsi Kalimantan Selatan dan di beberapa tempat di Provinsi Kalimantan Timur dan Kalimantan Tengah disebut orang Banjar. Bahasa mereka disebut bahasa Banjar. $^{8}$

Masyarakat Banjar adalah kaum imigran Melayu dari Sumatera dan sekitarnya, yang sekitar lebih dari 1000 tahun yang lalu mendiami beberapa tempat di Pulau Kalimantan, terutama Kalimantan bagian Selatan. Kelompok masyarakat pendatang ini lebih dominan dibandingkan kelompok-kelompok masyarakat Dayak di sekitarnya. Ke dalam masyarakat Melayu ini bergabung atau melebur berbagai kelompok masyarakat Dayak, khususnya Dayak

\footnotetext{
${ }^{7}$ Djantra Kawi. Telaah Bahasa Banjar, (Banjarbaru: Scripta Cendekia, 2011), h. 1.

${ }^{8}$ Fudiat Suryadikara dkk, Kamus Besar Bahasa Indonesia, (Jakarta: Pusat Pembinaan dan Pengembangan Bahasa Indonesia Kemendikbud, 1981), h. 1.
} 
Pegunungan Meratus (bukit) dan Manyan, Ngaju, dan mungkin juga dari kelompok Lawangan. Unsur yang sangat kuat juga dalam masyarakat Banjar adalah unsur Jawa. Unsur-unsur lainnya seperti Bugis, dan Arab, yang hanya bersifat sebagian. Mereka semuanya menganggap dirinya sebagai orang Banjar dan mengembangkan bahasa Banjar. ${ }^{9}$

Nyanyian rakyat (masyarakat Banjar) atau folksong merupakan jenis sastra yang anonim, tidak diketahui siapa pencipta nyanyian tersebut. Oleh karena itu nyanyian rakyat menjadi milik kolektif masyarakat tertentu. Setiap anggota masyarakat itu merasa memiliki dan berusaha mewariskannya kepada generasi berikutnya.

Berbeda dengan kebanyakan bentuk-bentuk foklor lainnya, nyanyian rakyat berasal dari bermacam-macam sumber. Nyanyian rakyat lebih luas peredarannya pada suatu kolektif daripada nyanyian lainnya, dan dapat bertahan untuk beberapa generasi. Tempat peredaran nyanyian lebih luas. Umur nyanyian rakyat lebih panjang daripada nyanyian pop dan nyanyian lainnya. Bentuk nyanyian rakyat sangat berwarna, dari yang paling sederhana sampai yang sangat rumit. Ciri yang membedakan nyayian rakyat dari nyayian lainnya adalah sifatnya yang mudah dapat berubah. Hal ini sesuai dengan pendapat Danandjaya "nyanyian rakyat dapat dibedakan dari nyanyian lainnya, seperti nyanyian pop atau klasik (art song) karena sifatnya yang mudah berubahubah, baik bentuk maupun isinya" ${ }^{\text {"10 }}$. Contoh nyanyian rakyat yang mengalami perubahan pada lirik berikut:

\section{Laaa ilaabaaillallah}

Muhammadar Rasulullah

Dimana kambing balalah

Di higa rumah Rasulullah

Guring-guring anakev guring

Guringakan dalam ayunan

Matanya kalat bandak taguring

Nyanyian rakyat yang memakai lagu yang sama dengan lirik yang berbeda dapat dilihat pada teks lirik lagu berikut:

\section{Laa ilaahaiillallah \\ Mubammadur Rasulullah}

\footnotetext{
${ }^{9}$ Alfani Daud. Islam dan... h. 38.

${ }^{10}$ James Danandjaja, Folklor Indonesia: Ilmu Gosip, Dongeng, dan Lain-lain, Jakarta: Grafiti Press, 2002), h.142.
} 


\section{Tiada Tuhan selain Allah \\ Nabi Mubammad utusan Allah \\ Guring-guring anakeku guring \\ Kuguringakan dalam ayunan \\ Nabi Muhammad itu orangnya ramah tamah \\ Murah senyum lagi peramah \\ Halus budi pakartinya lagi pemurah.}

Lirik lagu menidurkan anak itu berirama lembut, tenang dan berulangulang. Kata-katanya penuh kasih sayang, karena berisikan bujukan agar si anak atau cucu mau memejamkan matanya. Dalam lirik lagu menidurkan anak masyarakat Banjar juga selalu terselip doa dan harapan, serta nasihat. Walaupun teks liriknya berbeda-beda tetapi kebanyakan dilagukan dengan irama yang mirip satu dengan lainnya. Karena bentuk lagunya diturunkan secara turun temurun, sedangkan liriknya dapat berbeda-beda tergantung dari orang yang menuturkan sebelumnya (penyanyi hanya menirukan lagu dari penyanyi pendahulunya). Hal ini sesuai dengan pendapat $\operatorname{Lord}^{11}$ yang menyatakan ada tiga tahap dalam proses komposisi atau cara pemerolehan lagu secara lisan, yaitu peletakan fondasi dengan cara mendengarkan atau melakukan penyerapan, penerapan atau aplikasi, dan pelantunan di hadapan pendengar. Menurutnya, ketiga proses komposisi tersebut senantiasa diikuti atau dilanjutkan dengan proses mengakumulasi, mengombinasikan, dan memodelkan kembali formula yang telah ada. Lord juga menjelaskan bahwa penyair lisan dalam melantunkan puisi lisan (lagu) tidak akan sama persis, meskipun bersumber dari puisi lisan yang sama. Hal ini disebabkan penyair lisan hanya menghafalkan formulanya saja sehingga ketika melantunkan puisi lisan (dalam performance) terdapat perubahan, penambahan, atau kesalahan.

Di samping itu, lirik lagu menidurkan dan maayun anak juga berisi doa dan harapan. Bagi orang Banjar yang mayoritas beragama Islam, dalam kehidupannya sehari-hari, doa merupakan sesuatu yang sangat penting. Apalagi doa yang disampaikan oleh seorang ibu dalam menidurkan dan maayun anaknya, sambil maayun ia menyanyikan lagu yang berisi doa untuk anaknya. Hal ini sebagai sebuah refleksi dari harapan seorang ibu terhadap anak-anaknya dan merupakan media komunikasi yang sangat efektif dalam menjalin hubungan kedekatan kasih sayang antara ibu dan anak. Itu dapat dilihat pada contoh lirik lagu berikut ini:

${ }^{11}$ Alberd B. Lord, The Singer of Tales, Edisi II, (London England: Harvard University Press, 2001), h. 21. 


\section{Guring-guring anakeku guring \\ Guring diakan dalam ayunan \\ Anakeku nang bungas lagi bauntung \\ Hidup baiman mati baiman.}

Lirik lagu menidurkan anak pada masyarakat Banjar juga ada yang berisi kalimat-kalimat tauhid. Dengan mendendangkan lirik lagu yang berisi kalimat tauhid tersebut orang tua berusaha menanamkan pendidikan karakter dan mengenalkan nilai-nilai karakter keagamaan (relegius) kepada anaknya sejak dini. Hal ini sesuai dengan sebuah riwayat yang menyatakan bahwa menuntut ilmu itu dimulai dari buaian sampai ke liang lahat. Biasanya lirik lagu menidurkan anak yang berisi ajaran tauhid selalu dimulai dengan kalimat syahadat. Berikut ini contoh lirik lagu manidurkan anak dengan kalimat tauhid.

Laaa ilaabaiillallah

Mubammadur Rasulullab

Tiada Tuban selain Allab

Nabi Mubammad Utusan Allah

Guring-guring anakeku guring

Guring diakan dalam ayunan

Guring-guring anakeku guring

Matanya kalat dibawa guring

Laaa ilaah haiillallah

Tiada Tuban selain Allab

Nabi Mubammad ya Rasulullab

Nabi Mubammad utusan Allah

Asam kandis asam galugur

Kadua asam si riang-riang

Manangis di pintu kubur

Taringat badan tidak sembabyang.

Selanjutnya, lirik lagu menidurkan anak pada masyarakat Banjar ada yang berbentuk pantun. Pantun Banjar adalah jenis puisi lama yang menggunakan bahasa Banjar. Pantun-pantun yang disampaikan berisikan harapan dan keinginan orang tua kepada anaknya, agar anaknya mendapatkan kehidupan yang baik dan sejahtera di masa depan. Berikut contoh lirik lagu yang berupa pantun.

Amun saluang si maki-maki

Amun diandak di piring putih

Lamun bacucu si laki-laki 


\section{Mambawa untung mambawa sugib \\ Batanam nyiur ada banyunya, \\ Banyunya lilih ka batang. \\ Mudahan panjang umurnya, \\ Satu bahaya nang jangan datang.}

\section{BENTUK LIRIK LAGU MENIDURKAN ANAK PADA MASYARAKAT BANJAR}

Berdasarkan bentuknya, lirik lagu menidurkan anak pada masyarakat Banjar sebenarnya lebih sesuai digolongkan ke dalam bentuk puisi bebas, yang tidak terlalu terikat kepada aspek baris, rima dan jumlah kata dalam setiap bait, namun berdasarkan data yang penulis temukan di lapangan, terdapat 2 bentuk lirik lagu menidurkan anak pada masyarakat Banjar, yakni lirik lagu menidurkan anak bentuk bebas dan lirik lagu menidurkan anak bentuk terikat.

Lirik lagu menidurkan anak bentuk bebas adalah lirik lagu yang digubah tanpa rujukan konvesi bentuk sama sekali. Tidak ada rujukan jumlah kata dalam satu baris, maupun jumlah baris dalam satu bait. Konvensi bentuk yang dirujuk hanya menyangkut pola persajakan saja, yakni sajak awal, sajak dalam, dan sajak akhir. Posisi kata bersajak awal, dalam bersajak dalam, dan bersajak akhir itu dapat terjadi pada satu baris yang sama (bersajak horizontal) atau pada baris yang berbeda (bersajak vertikal pada satu bait yang sama). Berikut contoh lirik lagu bentuk bebas.

Laaa ilah haillallah

Mubammad Rasullullah

Wujud

Qidam

Baqa

Mukhalafatubu Lil hawadisi

Qiyamubu bi Nafsibi

Wabdaniyah, Qudrah, dan iradah

Laailah ba illallab

Muhammad Rasulullab

Ilmu, Hayah, Sama, Basar

Qadiran, Muridan, Aliman

Hayyan, Sami'an, Basiran, Mutakaliman

Laa ilah haillallah

Mubammad Rasulullab 
Adapun bentuk terikat, lirik lagu menidurkan anak pada tulisan ini berbentuk puisi lama yang berjenis pantun. Pantun termasuk salah satu jenis puisi dalam tradisi sastra Banjar. ${ }^{12}$ Pantun Banjar adalah jenis puisi lama yang menggunakan bahasa Banjar. Lirik lagu menidurkan anak ini juga terdiri atas 5 variasi. Lirik lagu menidurkan anak pada masyarakat Banjar yang berbentuk pantun tiap baitnya terdiri atas empat baris. Dilihat dari sajaknya, bentuk pantun pada tulisan ini menggunakan sajak bervariasi, yaitu sajak silang (a-b-ab), sajak penuh (a-a-a-a), dan sajak peluk (a-b-b-a). Tiap barisnya biasanya berisi empat kata. Baris pertama dan kedua pada lirik lagu ini berfungsi sebagai tumpuan (sampiran), sedangkan baris ketiga dan keempatnya merupakan isi.

Adapun contoh lirik lagu menidurkan anak bentuk terikat 1 adalah:

Guring-guring cucuku guring

Guring-guring

Guringakan dalam ayunan

Tabuk sumur si tanah liat $(2 x)$

Ada banyunya kumandiakan

Ada umur ada wasiat $(2 x)$

Tahun dudi ku jadiakan

Guring-guring cucuku guring

Guringdiakan dalam ayunan

Tamban bamban jangan di parit (2x)

Kalu di parit di pinggir sumur.

Hati dandam jangan diarit $(2 x)$

Kalu diarit membawa umur.

Dadung si Dadung cucuku kacil

Dadung

Handaknya guring matanya kalat

Dalam ayunan

Lirik lagu menidurkan anak bentuk terikat 2 dalam tulisan ini dapat dikenali yaitu baris pembuka tidak ada, baris isi bentuknya berupa pantun (ada sampiran dan isi). Pantun menggunakan sajak penuh (a-a-a-a), bait 1,3. Adanya

${ }^{12}$ Maskuni, Sastra Daerah Kabupaten Barito Kuala, (Marabahan: Dinas Lingkungan Hidup, Kebersihan, Pariwisata dan Budaya Kabupaten Barito Kuala, 1997), h. 11. 
kosa-kata dengan vokal akhir (aw/was/aw/was) saling bersajak secara vertikal di baris satu, dua, tiga dan empat a/a/a/a (Tabuniaw/ pirawas/ maningaw/ lawas), data ini merujuk pada gaya bahasa perulangan yang disebut asonansi, yakni sejenis gaya bahasa repetisi yang berwujud perulangan vokal yang sama (di akhir kata). ${ }^{13}$ Bentuknya berupa puisi bebas ( bait 3). Suku kata dalam setiap bait lirik lagu ini berkisar 9-10 suku kata dalam setiap lariknya. Baris penutup tidak ada. Contoh lirik lagunya sebagai berikut:

Ayun-ayun ading ku ayun

Ayun ading dalam pukungan

Ayun-ayun sayangku ayun

Ayu ading kita guringan

Ka Sarapat ka Tabuniaw

Buah kuranji batang pirawas

Rasa panat gulu maningaw

Uma bajanji kada pang lawas

Nyiur gading di Taluk Selong

Pecah mangkuk di padaringan

Mata ading bisa mancalung

Mun kada guring bahabarian

\section{MAKNA LIRIK LAGU MENIDURKAN ANAK PADA MASYARAKAT BANJAR}

Makna lirik lagu menidurkan anak pada masyarakat Banjar ini dapat diketahui melalui langkah-langkah yang dilakukan dalam menapsirkan makna, pembacaan secara hermeneutika dilakukan lebih dahulu sebelum analisis lebih lanjut. Untuk memudahkan pemahaman, di sini lirik lagu sebagai data hasil tulisan "dibaca" secara keseluruhan lebih dahulu untuk mengetahui makna totalitasnya, kemudian untuk dapat lebih memaknai dan mengkonkretisasi lirik lagu lebih lanjut secara keseluruhan bacaan (tafsiran) lirik lagu menidurkan anak tersebut.

Berdasarkan analisis data, hasil tulisan menunjukan bait-bait lirik lagu menidurkan anak pada masyarakat Banjar mengandung makna semantik sesuai konsep yang dikemukakan Leech $^{14}$ yang meliputi makna konseptual, makna

\footnotetext{
${ }^{13}$ Henry Guntur Tarigan, Pengajaran Gaya Bahasa, (Bandung: Angkasa, 1985), h. 182.

${ }^{14}$ Geofrey Leech, Prinsip-Prinsip Pragmatik, (Jakarta: Universitas Indonesia, 1981), h. 47.
} 
asosiatif yang meliputi makna konotatif, makna sosial, makna afektif, makna reflektik dan makna kolokatif dan makna pragmatik. Munculnya makna-makna tersebut tidak terlepas dari bentuk (tipologi, diksi, stilistika) dan fungsi lirik lagu.

Berdasarkan konsep makna yang dikemukakan Leech tersebut, maknamakna yang dapat diidentifikasi melalui analisis lirik lagu menidurkan anak pada masyarakat Banjar dapat dijabarkan sebagai berikut:

Makna konseptual yang dapat diidentifikasi melalui analisis lirik lagu menidurkan anak pada masyarakat Banjar dalam tulisan ini mencakup penggunaan kata-kata dalam bait-bait lirik lagu mengandung makna denotatif yang memiliki kandungan logis dan kognitif. Berkaitan sebagai sifat khasnya sebagai salah satu genre karya sastra yang memungkinkan munculnya interpretasi makna terhadap kata-kata yang digunakan, maka makna konseptual dalam baitbait lirik lagu menidurkan anak ini perannya semakin mengecil. Peran dan posisinya yang semakin mengecil tergeser oleh hadirnya makna-makna lain yang muncul sebagai akibat interpretasi makna pada lirik lagu menidurkan anak yang mengandung makna denotasi.

Empat jenis makna yang termasuk ke dalam makna asosiatif yang dapat diidentifikasi pemunculannya melalui analisis makna bait-bait lirik lagu menidurkan anak adalah, makna konotatif yang dapat diidentifikasi melalui analisis makna dalam tulisan ini meliputi penggunaan kata-kata yang mengandung dan mengungkapkan asosiasi terhadap apa yang diacunya. Mengingat sifat khas karya sastra khususnya genre puisi, tentu saja munculnya asosiasi terhadap apa yang diacu oleh penggunaan kata-kata dalam bait-bait lirik lagu tidak terlepas dari hasil interpretasi. Namun, identifikasi terhadap kandungan makna untuk menentukan bait-bait yang mengandung makna konotatif tetap berpedoman pada hasil triangulasi data dan interpretasinya dalam analisis makna, memunculnya makna konotatif. Asosiasi terhadap katakata yang digunakan dalam lirik lagu di atas menimbulkan konotasi tertentu terhadap apa yang diacunya, dan dapat dijadikan sebagai dasar untuk menyatakan bait lirik lagu mengandung makna konotatif.

Berdasarkan tulisan ini proses penciptaan lirik lagu menidurkan anak pada masyarakat Banjar diturunkan dari penyanyi pendahulunya kepada generasi selanjutnya, lagu tersebut dibawakan bisa dengan lirik yang diciptakan kembali secara spontan yang disesuaikan dengan minat dan tujuan si penyanyi, keadaan pembawaannya, dan waktu pembawaannya. Sehingga lirik lagu tersebut bisa berubah-ubah, bertahan dan hidup karena selalu diciptakan dan 
dihayati kembali sesuai dengan daya cipta pembawa maupun penikmatnya. Yang tetap pada isi lirik lagu bukan alur cerita melainkan kelompok-kelompok ide yang disediakan oleh konvensi. Dengan bantuan formula dan ungkapanungkapan formulaik yang sudah baku, kelompok-kelompok ide itu dirakit menjadi sebuah bentuk lirik lagu yang utuh. Ini sesuai dengan teori Milman Parry dan Albert B. Lord. Menurut teori mereka, proses penciptaan sastra lisan dapat dicermati dari cara mereka memamfaatkan persediaan formula yang siap pakai sesuai dengan konvensi sastra yang berlaku.

\section{FUNGSI LIRIK LAGU MENIDURKAN ANAK PADA MASYARAKAT BANJAR}

Menurut hemat penulis fungsi bahasa yang dapat diidentifikasi di dalam lirik lagu menidurkan anak pada tulisan ini dapat dijabarkan berikut ini.

\section{Fungsi informasional}

Fungsi ini berkaitan dengan bentuknya sebagai karya sastra yang dimanfaatkan sebagai media informasi. Menurut seorang informan, Mina, saat wawancara lirik lagu menidurkan anak ini dinyanyikan pada saat menidurkan anak karena berisi informasi mengenai bagaimana sejarah kehidupan Nabi Muhammad dan bagaimana masyarakat harus berperilaku dalam kehidupan sehari-hari mencontoh kehidupan Nabi. Contoh lirik lagu yang mengemban fungsi informasional dalam tulisan ini sebagai berikut:

\section{Laaa ilaabaiillallah}

Mubammadur Rasulullah

Tiada Tuhan selain Allah

Nabi Mubammad utusan Allah

Guring-guring anakku guring

Kuguringakan dalam ayunan

Nabi Muhammad itu orangnya ramah tamah

Murah senyum lagi peramah

Halus budi pakartinya lagi pamurah

Laa ilaahaillah al malikul hakkul mubin

Muhammadur Rasulullah shadikul wa'dul amin

Nabi Mubammad itu Nabi dan Rasul akbir zaman

Tutur sapanya jadi panutan 


\section{Tingkeah lakunya jadi contoh teladan \\ Gasan umatnya sampai akhir zaman}

Penulis berhasil menemukan 4 buah lirik lagu menidurkan anak pada masyarakat Banjar berfungsi informasional.

\section{Fungsi Ekspresif}

Lirik lagu menidurkan anak mengemban fungsi ekspresif karena termasuk karya sastra yang berbentuk puisi yang merupakan ekspresi pikiran, perasaan, sikap, dan pengalaman dari orang tua yang telah lebih banyak memakan asam, garam. Pikiran, perasaan, sikap, dan pengalaman yang diekspresikannya tersebut adalah hasil perenungan yang mendalam terhadap segala macam, rintangan dan tantangan yang dihadapi selama hidup di dunia ini, sehingga terciptalah lirik lagu menidurkan anak yang berisi nasihat.

Dalam hubungannya dengan fungsi ekspresif, Hj. Aminah mengatakan ${ }^{15}$ lirik lagu menidurkan anak bisa difungsikan untuk memberikan nasihat pada anak di saat mau tidur, nasihat tersebut berfungsi pedagogis yakni, anak harus mematuhi nasihat orang tuanya, anak harus mematuhi pesan atau wasiat orang tuanya, anak harus berbakti kepada orang tua, menanamkan pengajaran Islam Lirik lagu juga merupakan lirik lagu yang dinyanyikan keluarganya (dari orang tua beliau sampai kepada beliau) pada saat menidurkan anak atau cucu rebahan di kasur atau tempat tidur. Sambil rebahan menepuknepuk pantat anak atau cucu atau sambil mengelus-elus punggung dan kepala anak dengan perlahan, penuh kasih sayang sampai anak tertidur. Menurut beliau juga cara ini sebagai bentuk ekspresi rasa kasih sayang seorang ibu atau nenek yang sedang mengasuh bayinya (anaknya). Usia anak yang ditidurkan berkisar antara 2 sampai 5 tahun.

\section{Fungsi Estetis}

Lirik lagu menidurkan anak pada masyarakat Banjar yang beragam (multi bentuk) menunjukan bahwa bahwa etnis Banjar di Kalimantan Selatan merupakan suku bangsa yang kreatif dalam mengolah kosa-kata biasa menjadi sebait puisi (lirik lagu) yang efonis, stilis. Dimensi efonis dan stilis merujuk kepada citarasa estetik bernuansa sastra. Lirik lagu menidurkan anak yang berbentuk pantun pada tulisan ini mengemban fungsi estetik karena kapasitasnya sebagai salah satu genre sastra. Sebagai salah satu genre sastra, lirik

\section{Barabai, Kab. HST.}


lagu menidurkan anak masyarakat Banjar tidak terlepas dari sifat karya sastra yang mengandung nilai-nilai keindahan (estetika).

Karena sifat khas karya sastra yang mengandung nilai-nilai keindahan, dengan sendirinya bait-bait dalam lirik lagu menidurkan anak mengemban fungsi estetik. Dengan demikian, fungsi estetik diemban oleh keseluruhan bait syair yang terdapat dalam lirik lagu menidurkan anak.

\section{Fungsi Direktif}

Lirik lagu menidurkan anak pada masyarakat Banjar mengemban fungsi direktif karena termasuk genre sastra yang dimanfaatkan oleh masyarakat Banjar yang masih menggunakan lirik lagu di saat menidurkan anaknya sebagai media untuk menyampaikan pesan, nasihat, doa dan permohonan, pendidikan dan ajaran-ajaran tentang nilai-nilai kebenaran. Lirik lagu menidurkan anak yang mengandung fungsi direktif perintah dapat dilihat pada lirik lagu menidurkan anak berikut.

Yun ayun anakku ratu

Lakas bapajam lakasi guring

Matanya kalat bawa bapajam

Yun ayun anakeku ayun

Ayun dalam shalawat $\mathrm{Nabi}$

Jauh culas jaubkan dangki

Kur sumangat bidup baiman

\section{Yun dimana anakke guring \\ Guring anakeku dalam Bismillah \\ Bawakan bulan bawakan bintang}

Hasil wawancara dengan ibu Juraida menyimpulkan bahwa lirik lagu menidurkan anak difungsikan sebagai doa atau permohonan untuk cucunya, beliau berharap cucunya kalau besar seperti kata-kata yang ada pada lirik lagu yang dinyanyikan beliau yaitu panjang umur, berguna bagi keluarga, agama dan bangsa. Biasanya beliau menyanyikan lirik lagu ini ketika menidurkan cucu beliau yang berumur 7 bulan dalam ayunan.

Lirik lagu menidurkan anak juga menurut ibu Aminah dinyanyikan ketika menidurkan anak di tempat tidur. Lirik lagu ini juga berfungsi sebagai penanaman karakter pada anak, mengajarkan kepada anak supaya berbuat baik, rajin belajar dan membantu orang tua. Hal ini berkaitan dengan karakter fungsinya yang juga positif, yakni sebagai media pendidikan, pedoman tingkah 
laku (norma), dan pengaturan aspek-aspek kehidupan pada masyarakat Banjar. Penulis berhasil menemukan 7 buah lirik lagu menidurkan anak berfungsi direktif.

Analisis yang berkaitan dengan fungsi bahasa (wacana) dalam lirik lagu menidurkan anak berpedoman pada fungsi-fungsi bahasa secara umum menurut konsep Leech ${ }^{16}$ yang meliputi fungsi informasional, fungsi ekspresif, fungsi direktif, fungsi estetik dan fungsi fatik.

Jenis-jenis fungsi bahasa yang dapat diidentifikasi di dalam lirik lagu menidurkan anak pada tulisan ini dapat diklasifikasikan menjadi empat jenis yaitu, fungsi informasional, fungsi ekspresif, fungsi estetik, dan fungsi direktif. Keempat fungsi bahasa tersebut ditunjang oleh aspek bentuk melalui pemanfaatan unsur tipologi (struktur bentuk lirik), unsur diksi yang meliputi penggunaan sinonim, antonim dan unsur stalistika yang meliputi gaya dan penggunaan bahasa kiasan sebagai sarana retorika. Fungsi-fungsi tersebut memunculkan aspek makna. Setiap fungsi yang dibawa oleh bait-bait lirik lirik lagu menidurkan anak yang berkaitan erat dengan hadirnya makna. Di samping fungsi di atas lirik lagu menidurkan anak memiliki fungsi dalam kehidupan sehari-hari di antaranya sebagai sarana pendidikan, sebagai sarana komunikasi, dan sebagai penyampaian nasihat dalam persaudaraan.

Dalam hal penikmat estetik dalam tulisan ini ditemukan perbedaan antara menyenangkan dan berguna, pandangan bahwa penikmat estetik murni sesungguhnya belum ada. Hanya bahasa yang diciptakan tukang cerita lisan (penyanyi) itu memberikan efek estetis, tetapi fungsi utamanya adalah mengamankan sistem nilai dalam masyarakat Banjar secara turun temurun. Jadi fungsi estetis pada lirik lagu menidurkan anak di sini lebih mengutamakan fungsi berguna daripada menyenangkan, sekalipun fungsi itu sendiri dapat pula menimbulkan kenikmatan estetis. Penyanyi (ibu, nenek, kakak) memamfaatkan sarana bahasa untuk mencapai efek maksimal terhadap pendengar (anak, cucu) yang hendak diyakinkanya, agar lebih mudah dalam menanamkan nilai-nilai pada generasi penerusnya.

Fungsi lirik lagu menidurkan anak pada tulisan ini juga dianggap sebagai media yang tepat untuk melakukan pembinaan mental, pendidikan secara informal sejak dini kepada anak-anak dan cucunya. Ini bisa dilihat dari isi lirik lagu menidurkan anak yang mengisahkan cerita Nabi, kearifan, dan contohcontoh mengenai kehidupan dapat memberikan nilai-nilai atau norma tentang agama, akhlak, budi pekerti dan moral.

${ }^{16}$ Geofrey Leech, Prinsip-Prinsip..... h. 86. 
Fungsi lirik lagu sebagai media pendidikan, yakni sebagai pedoman tingkah laku dan pengatur aspek-aspek kehidupan. Pengajaran nilai-nilai luhur dimaksud dilakukan secara tidak langsung melalui nyanyian lirik lagu menidurkan anak berkonotasi nasihat, petuah dan pesan-pesan moralitas atau etika sosial yang dapat dijadikan sebagai pedoman hidup dan pengarah tingkah laku anak sebagai bagian dari masyarakat atau orang perorang.

\section{SIMPULAN}

Pada tulisan Lirik Lagu Menidurkan Anak pada Masyarakat Banjar ini penulis telah melakukan analisis mengenai kajian bentuk, makna dan fungsinya secara terinci dan mendalam. Berdasarkan analisis penulis bentuk lirik lagu menidurkan anak pada Masyarakat Banjar memiliki dua bentuk, yaitu: pertama, lirik lagu menidurkan anak pada masyarakat Banjar bentuk bebas; kedua, lirik lagu menidurkan anak pada Masyarakat Banjar bentuk terikat.

Makna bahasa yang terkandung di dalam lirik lagu menidurkan anak pada masyarakat Banjar ini memiliki makna yang sangat luas dan berbeda-beda, namun setelah dianalisis penulis menyimpulkan bahwa, secara umum makna lirik lagu menidurkan anak pada masyarakat Banjar memperlihatkan bahwa bait-bait syair tersebut mengandung makna sematik, yang meliputi makna konseptual, makna asosiatif yang meliputi makna konotatif, makna sosial, makna afektif, makna reflektif, makna kolokatif, makna tematik, dan pragmatik. Munculnya makna-makna tersebut tidak terlepas dari bentuk dan fungsi lirik lagu menidurkan anak. Keterkaitan antara makna dan fungsi sebagai akibat bentuk pemakaian bahasa.

Makna sematik (konseptual) dan makna pragmatik (lokusi) berkaitan erat dengan fungsi informasional. Antara makna dengan fungsi terjalin hubungan yang saling berkaitan dan saling mendukung. Hadirnya makna konseptual dari segi sematis dan makna lokusi dari segi pragmatik terlihat dari fungsi informasional dan sebaliknya. Makna asosiatif yang meliputi makna konotatif, sosial, afektif, reflektif, dan ekspresif dan fungsi estetis yang secara implisit bermuara pada fungsi direktif.

Lebih rinci lirik lagu menidurkan anak pada masyarakat Banjar yang telah dianalisis didapatkan empat ragam/jenis fungsi bahasa, yakni sebagai berikut.

1. Lirik lagu menidurkan anak pada masyarakat Banjar fungsi informasional, yakni karya sastra yang dimanfaatkan sebagai media informasi. 
2. Lirik lagu menidurkan anak pada masyarakat Banjar berfungsi ekspresif. Sebagai karya sastra yang berbentuk puisi yang merupakan ekspresi pikiran, perasaan, sikap, dan pengalaman dari orang tua yang telah lebih banyak berpengalaman mengenai hidup, sehingga terbentuklah lirik lagu menidurkan anak yang berupa nasihat, baik itu nasihat yang berhubungan dengan tingkah laku, maupun nasihat mengenai kehidupan yang dijalani.

3. Lirik lagu menidurkan anak pada masyarakat Banjar berfungsi direktif, yakni karya sastra yang dimanfaatkan sebagai media untuk menyampaikan pesan, nasihat, doa (harapan), pendidikan dan ajaranajaran tentang nilai-nilai kebenaran.

4. Lirik lagu menidurkan anak pada masyarakat Banjar fungsi estetis, adalah karya sastra yang mengandung nilai-nilai keindahan (estetika). Karena sifat khas karya sastra yang mengandung nilai-nilai keindahan, dengan sendirinya bait-bait syair dalam lirik lagu menidurkan anak pada masyarakat Banjar mengemban fungsi estetik.

\section{DAFTAR PUSTAKA}

Akesson, Ingrid. 2012. Oral/Aural Culture in Late Modern Society? Traditional Singing as Professionalized Genre and Oral-Derived Expession, Jurnal Oral Tradition, Volume 27, Nomor 1, Columbia: University of Missouri.

Andianto, M. Rus. 1987. Sastra Lisan Dayak Ngaju. Jakarta: Pusat Pembinaan dan Pengembangan Bahasa. Departemen Pendidikan dan Kebudayaan.

Campbell, Katherine. 2012. Masonic Song in Scotland: Folk. Tunes and Community. Jurnal Oral Tradition, Volume 27, Nomor 1, Columbia: University of Missouri.

Chaer, Abdul. 2007. Linguistik Umum. Jakarta: PT Rineka Cipta.

Chaer, Abdul. 1996. Pengantar Semantik Bahasa Indonesia. Jakarta: Penerbit Rineka Cipta. Cetakan II.

Chamamah-Soeratno, Siti. 2011. Sastra: Teori dan Metode, Cet. I, Yogyakarta: Jurusan Sastra FIB UGM dan Program S2 Ilmu Sastra FIB UGM dan Elmatera.

Condrat, Riastinadya. 2012. Mantra Dayak Maanyan, Kajian Bentuk, Fungsi, dan Makna. (Tesis). Banjarmasin: FKIP Unlam. 
Danandjaya, James. 2002. Foklor Indonesia: Ilmu Gosip, Dongeng, dan Lain-lain. Jakarta: Grafiti Press.

Danesi, Marcel. 2011. Pesan, Tanda, dan Makna. Yogyakarta: Jalasutra.

Daud, Alfani. 1997. Islam dan Masyarakat Banjar: Deskripsi dan Analisis Kebudayaan Banjar. Jakarta: PT Raja Grafindo Persada.

Desriani, Erlita dan Rustam Effendi. 2013. "Struktur Wacana, Makna, dan Fungsi Mahalabiu" Jurnal Babasa dan Sastra.3 (1):114.

Djajasudarma, Fatimah. 1993. Semantik I Pengantar Kearah Ilmu Makna. Bandung: PT Eresco Bandung.

E. Palmer, Richard. 2005. Hermeneutics Interpretation Theory in Scbleirmacher, Dilthey, Heidegger, and Gadamer diterjemahkan oleh Masnuri Hery dan Damanhuri dengan judul Hermeneutika; Teori Baru Mengenai Interpretasi. Cet.II. Yogyakarta: Putaka Pelajar.

Effendi, Rustam. 2011. Sastra Banjar, Teori dan Interpretasi. Banjarbaru: Scripta Cendekia.

Ganie, Tajuddin Noor. 2013. Karakteristik, Bentuk, Fungsi, Makna, dan Nilai Peribahasa Banjar, Banjarmasin: Rumah Pustaka Foklor Banjar.

Hadi, W. M. Abdul. 2014. Hermenentika Sastra Barat \& Timur. Jakarta: Sandra Press.

Hamdju, Atan. 1987. Buku Pengetahuan Seni Musik. Jakarta: PT. Mutiara Sumber Widya.

Hapip, Abdul Djebar. 2006. Kamus Banjar-Indonesia. Banjarmasin: CV Rahmat Hafiz Al Mubaraq.

Hutomo, Suripan Sadi. 1991. Mutiara Yang Terlupakan. Surabaya: Himpunan Sarjana Kesusastraan Indonesia.

Jabrohim (Ed.). 2012. Teori Penelitian Sastra. Yogyakarta: Pustaka Pelajar.

Kawi, Djantera. 2011. Telaah Bahasa Banjar. Banjarbaru: Scripta Cendekia.

Kosasih, E. 2004. Intisari Bahasa dan Sastra Indonesia. Bandung: Pustaka Setia.

Kurniawan, Heru. 2009. Mistisisme Cahaya. Yogyakarta: Grafindo Literatur Media.

Lambut, MP. 2011. Pengajaran Sastra: Refleksi Pengalaman Pribadi, tidak diterbitkan. Banjarmasin: FKIP Unlam.

Leyh, Gregory. 1992. Legal Hermeneutics: History, Theory, and Practice. California: University of California Press.

Leech, Geofrey. 1993. Prinsip-Prinsip Pragmatik. (Terj. M. D. D. Oka). Jakarta: UI Press. 
Lord, Albert B. 2000. The Singer Of Tales. Edisi II, London England: Harvard University Press.

Maskuni. 2008. Sastra Daerah Kabupaten Barito Kuala. Marabahan: Dinas Lingkungan Hidup,Kebersihan, Pariwisata dan Budaya Kabupaten Barito Kuala.

Nyahu, Anthony. 2010. Ayo Belajar Bahasa Dayak Ngaju. Yogyakarta: Penerbit Pintu Cerdas. Cetakan I

Palmer, Richard E. 1969. Hermeneutics: Interpretation Theory in Schleiermacher, Dilthey, Heidegger, and Gadamer. Evanston: Northwestern University Press.

Pateda, Mansoer. 2001. Semantik Leksikal. Jakarta: PT Rineka Cipta. Cetakan I.

Patilima, Hamid. 2011. Metode Penelitian Kualitatif. Bandung: Alfabeta.

Pemerintah Provinsi Kalimantan Selatan, Sastra Indonesia Modern di Kalimantan Selatan Sebelum Perang (1930-1945). 2011. Banjarmasin: Dinas Pemuda dan Olah Raga.

Permata, Yuni. 2011. Analisis (Mantra Dayak Ngaju) Bentuk, Fungsi, dan Maknanya. (Tesis). Banjarmasin: FKIP UNLAM.

Poerwadarminta,WJS. 1976. Kamus Umum Bahasa Indonesia. Jakarta: Penerbit Balai pustaka.

Pradopo, Rachmat Djoko. 2002. Kritik Sastra Indonesia Modern. Yogyakarta: Gama Media.

Pradopo, Rachmat Djoko dkk. 2003. Metodologi Penelitian Sastra. Yogyakarta: Hanindita Graha Widya.

Pradopo, Rachmat Djoko. 2012. Beberapa Teori Sastra, dan Penerapannya. Yogyakarta: Pustaka Pelajar Yogyakarta. Cetakan IX.

Rafiek, M. 2010. Teori Sastra: Kajian Teori dan Praktik. Bandung: Refika Aditama.

Ramlan, M. 1992. Bahasa Konteks Dari Teks. Yogyakarta: Fakultas Universitas Gajah Mada.

Ratna, Nyoman Kutha. 2002. Paradigama Sosiologi Sastra.Yogyakarta: Pustaka Pelajar.

Ratna, Nyoman Khuta. 2010. Sastra dan Cultural Studies: Refresentasi Fiksi dan Fakta. Yogyakarta: Pustaka Pelajar.

Riffaterre, Michael. 1978. Semiotics of Poetry. Bloomington and London: Indiana Unversity Press.

Rosyidi, M. Ikhwan. 2010. Analisis Teks Sastra.Yogyakarta: Graha Ilmu.

Saberi. 2010. Mantra Banjar, Analisis Bentuk, Fungsi, Makna, Dan Penandanya. Tesis PSM. PBSID UNLAM. Banjarmasin: Tidak Diterbitkan. 
Semi, Atar. 2012. Metode Penelitian Sastra. Bandung: CV Angkasa.

Sobur, Alex. 2004. Semiotika Komunikasi, bandung: PT Remaja Rosdakarya.

Sudikan, Setya Yuwana. 2001. Metode Penelitian Sastra Lisan. Surabaya: Citra Wacana.

Sunarti.dkk.1977. Sastra Lisan Banjar. Banjarmasin: Proyek Penelitian Bahasa dan Sastra Indonesia dan Daerah Kalimantan Selatan Departemen Pendidikan dan Kebudayaan.

Sunarti. 1978. Bentuk-Bentuk Pantun Banjar dan Fungsinya dalam Masyarakat Banjar. Banjarmasin: Universitas Lambung Mangkurat.

Suryadikara, Fudiat dkk. 1981. Jakarta: Pusat Pembinaan dan Pengembangan Bahasa Departemen Pendidikan dan Kebudayaan.

Suryanata, Jamal T. 2012. Sastra di Tapal Batas; Tradisi Cerpen Banjar 1980-2000. Tanpa Tempat Terbit: Tahura Media.

Sweeney, Amin. Kajian Tradisi Lisan dan Pembentukan wacana Kebudayaan. Makalah seminar Internasional Tradisi Lisan III, Jakarta, 14-16 Oktober 1999.

Tarigan, Henry Guntur. 2011. Dasar-Dasar Psikosastra. Bandung: Angkasa.

Tarigan, Hendry Guntur. 1985. Pengajaran Gaya Bahasa, cetakan III, Bandung: Penerbit Angkasa.

Tarsyad, Tarman Effendi. 2011. Wacana Lokal Banjar dalam Puisi. Banjarmasin: Tahura Media.

Teeuw, A. 1984. Sastra dan Ilmu Sastra: Pengantar Teori Sastra. Jakarta: Dunia Pustaka Jaya Jakarta. Cetakan I.

Tim Penulis Universitas Negeri Malang. 2010. Pedoman Penulisan Karya Ilmiah. Malang: Universitas Negeri Malang.

Tuloli, Nani. 1991. Tanggomo: Salab Satu Ragam Sastra Lisan Gorontalo. Jakarta: Balai Pustaka.

Wahyu. 2009. Metode Penelitian Kualitatif. Banjarmasin: Universitas Lambung Mangkurat.

Wellek, Rene \& Austin Warren. 2014. Theory of Literature. Terjemah oleh Melani Budianta. Jakarta: PT Gramedia. 